\title{
Novel Nanoscale Tomography Modes in Materials Science
}

\author{
G. Möbus, B.J. Inkson
}

Sheffield University, Dept of Engineering Materials, Sheffield, S1 3JD, UK

Electron tomography of crystalline, inorganic, and heavy element containing nanomaterials is complicated by nonlinear, possibly non-monotonous, intensity relation during image formation, strong dependence on lattice plane orientation and potentially extreme exposure requirements. Very recent break-through results have been achieved in this field using new modes of image formation available in modern TEMs, comprising bright field, CTEM, STEM, HAADF, EFTEM, and EDX-mapping [1-5]. Three major groups of contrast seem to be most favourable (FIG. 1), sketched for two concentric cylinders of elements $A$ and $B\left(Z_{A}\right.$ and $\left.Z_{B}\right)$ :

- binary tomography: $\mathrm{I}_{0}=0, \mathrm{I}_{1}=\mathrm{I}_{2}=1$

- Z-Contrast imaging: $\mathrm{I}_{0}=0, \mathrm{I}_{1}=\mathrm{t}_{\mathrm{A}}(\mathrm{x}, \mathrm{y}) * \mathrm{Z}_{\mathrm{A}}{ }^{\mathrm{m}}, \mathrm{I}_{2}=\mathrm{t}_{\mathrm{A}}(\mathrm{x}, \mathrm{y}) * \mathrm{Z}_{\mathrm{A}}{ }^{\mathrm{m}}+\mathrm{t}_{\mathrm{B}}(\mathrm{x}, \mathrm{y}) * \mathrm{Z}_{\mathrm{B}}{ }^{\mathrm{m}}$

- Spectroscopic tomography: - tuned to $(A): I_{0}=0, I_{1}=I_{2}=t_{A}(x, y) * \sigma_{A}$

$$
\text { - tuned to }(B): I_{0}=0, I_{1}=0, I_{2}=t_{B}(x, y)^{*} \sigma_{B}
$$

Here, $\mathrm{t}(\mathrm{x}, \mathrm{y})$ is thickness, $\sigma$ an inelastic cross section, and $\mathrm{m}$ the atomic number exponent $(\mathrm{m}<2)$. In this simple picture, longitudinal coherence is neglected, and spectroscopic images are assumed processed into elemental maps (multi-window EFTEM). While HAADF-STEM is the most successful and universal "Z-contrast", other mechanisms such as weak-phase-object (WPO)-HREM, and various special cases of BF/DF-CTEM, e.g. high-angle hollow cone [1] , also classify as Zcontrast as of eq. (2). FIG. 1e sketches the topological class of objects which can be solved by binary tomography: Homogeneous phases $(\rho(x, y, z)=$ const.) of strictly convex shape on all crosssections perpendicular to the backprojection axis. Inversely, this is the class which can be sculptured by parallel beam tools (FIB, Laser cutter) from a rotating block. FIG. 2 shows experimental results obtained for spectroscopic tomography over $\pm 60^{\circ}$ tilt, using EFTEM/ESI, and $\pm 50^{\circ}$ EDX-mapping (step $10^{\mathrm{O}}$ ), as the imaging/ projection mechanisms [6, 7]. In FIG. 3, simulations demonstrate the theoretical capabilities of WPO-HREM at atomic resolution (ideal Si-crystal, cut into tip shape).

Outlook: The importance of spectroscopic tomography lies in eliminating thickness $\mathrm{t}(\mathrm{x}, \mathrm{y})$ as a parameter for quantification of composition in EELS and EDX. Furthermore, once the voxel size reduces (in future) to contain only one atom on average, interpretation will change: The element specific spectroscopic "4D-data space" after reconstruction would then consist of 1s and 0s only and can be largely compressed. The Z-contrast "3D data space" then contains no longer superpositions $\mathrm{Z}_{\mathrm{A}}{ }^{\mathrm{m}}+\mathrm{Z}_{\mathrm{B}}{ }^{\mathrm{m}}$, instead: $\mathrm{I}(\mathrm{x}, \mathrm{y}, \mathrm{z})=\mathrm{Z}_{\mathrm{i}, \mathrm{j}, \mathrm{k}}{ }^{m}$. With careful scaling and calibration of $m$, full spectroscopic information could then be claimed in 3D without a spectrometer; the 4D space becomes redundant.

[1] H. Kakibayashi, K. Nakamura, R. Tsuneta, Microsc.Microanal. 3 (Suppl. 2) (1997) 479.

[2] A.J. Koster et al., J phys chem., B 104, (2000) 9368.

[3] M. Koguchi et al., J. Electron Microsc. 50 (2001) 235.

[4] G. Möbus, B.J. Inkson, Appl. Phys. Lett., 79 (2001) 1369.

[5] P. Midgley et al., Chem.Communic.10 (2001) 907-908.

[6] G. Möbus et al., Microsc. Microanal. 7 (Suppl.2) (2001) 84, and Ultramicroscopy, in press (2003).

[7] G. Möbus et al., Mat.Res.Soc.Symp.Proc. 738, online (Fall-02; G1.2) and in press (2003). 

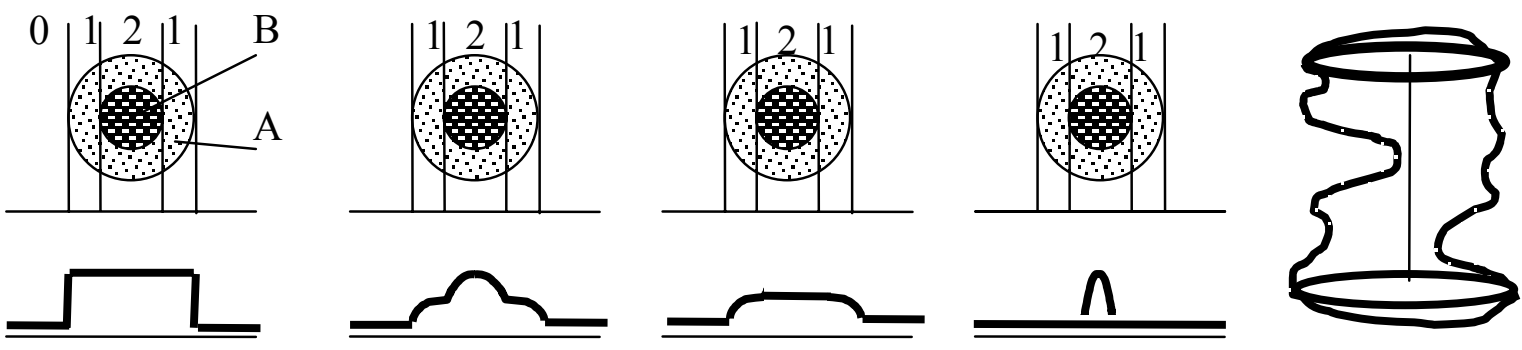

FIG. 1. (a-d) Four mechanisms of projected contrast (binary, Z-contrast, spectroscopic A and B). (e) class of objects with convex cross sections along backprojection axis.
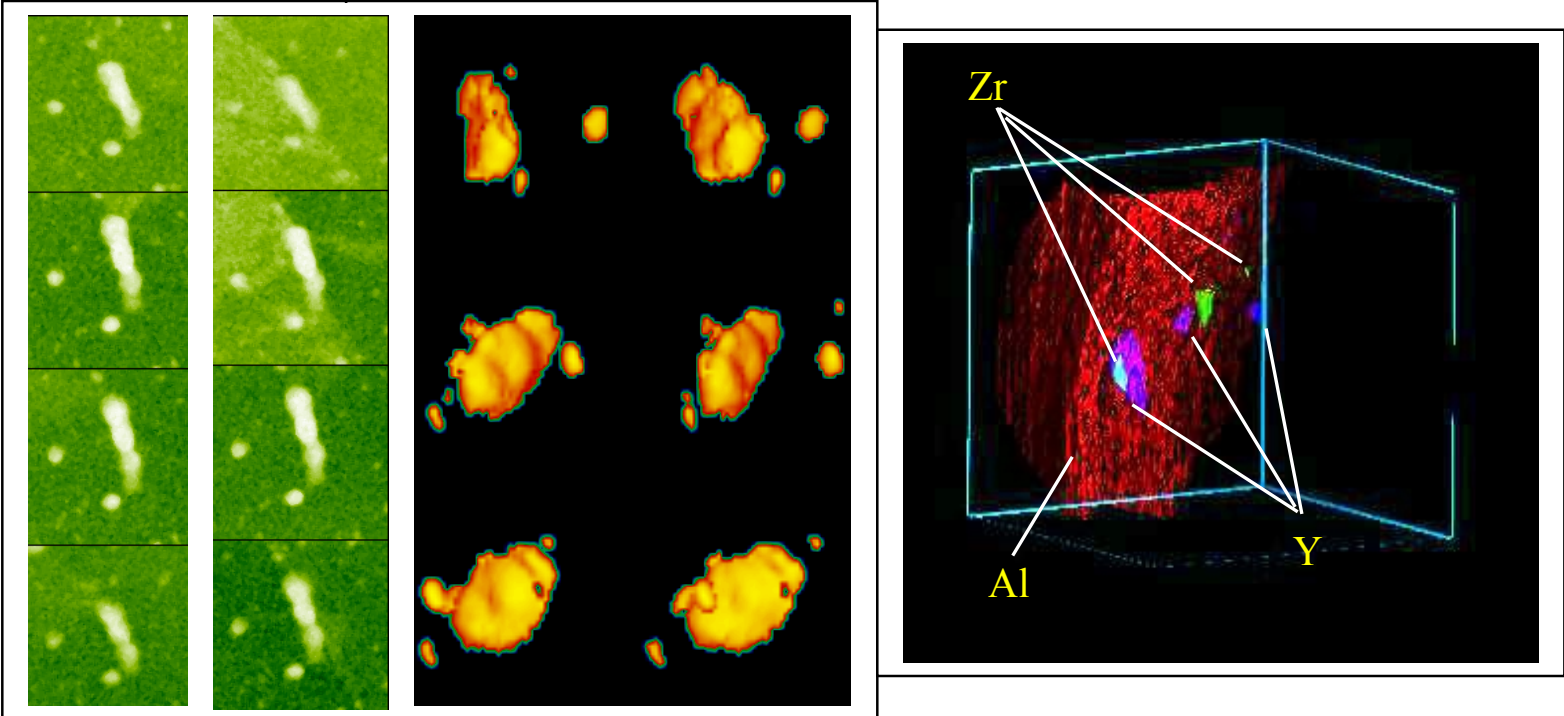

FIG. 2. (a) EFTEM tilt series of FeAl intermetallic alloy with $\mathrm{Y}_{2} \mathrm{O}_{3} / \mathrm{ZrO}_{2}$ particles, recorded at $\mathrm{Fe}$ L-edge inner shell loss; LEO-912 $\Omega$. (b) Reconstructed by filtered backprojection; threshold rending for $\mathrm{Y}_{2} \mathrm{O}_{3}$ particle shape. (c) Reconstruction of 3 spectroscopic energies from tilt series of EDX maps. B/W display (see CDROM for RGB-colour: red $=\mathrm{Al}$, blue $=\mathrm{Y}$, green $=\mathrm{Zr}$ ) of a superposition of Al, Y, Zr volume maps; same material as in (a,b); JEM 2010. For details see [6,7].
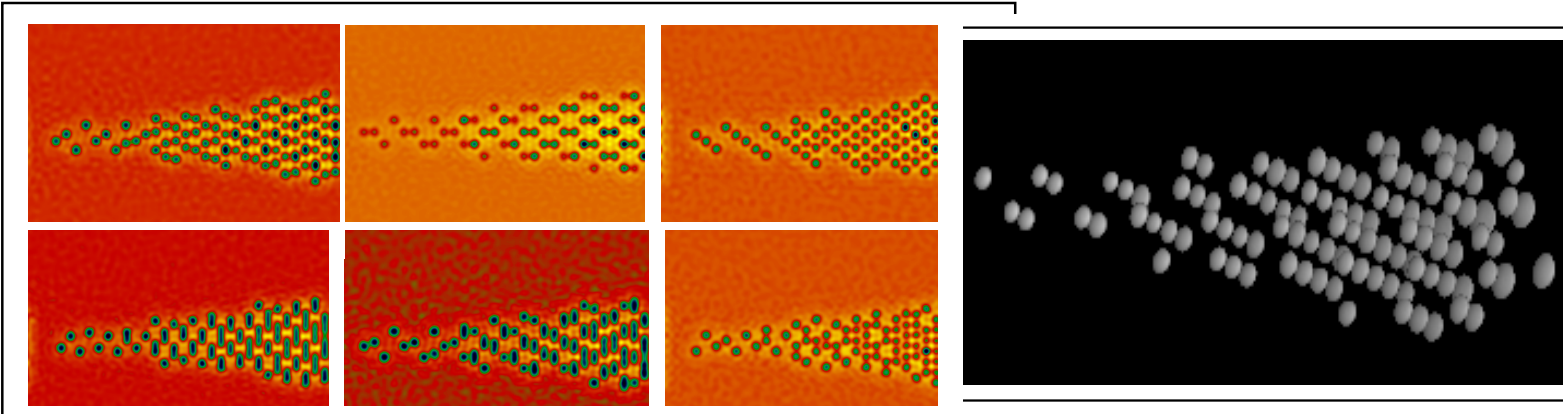

FIG. 3. (a) Silicon-tip, HREM simulations every $3^{\mathrm{O}}$ over $180^{\circ}$ (6 shown). (b) Reconstructed by linear backprojection (Optical data for JEM-ARM1250, Scherzer focus). 